\title{
Contamination of dental zirconia before final firing: Effects on mechanical properties
}

\author{
Seiji BAN ${ }^{1}$, Yuji OKUDA ${ }^{2,3}$, Makoto NODA ${ }^{3}$, Jiro TSURUKI ${ }^{4}$, Tatsushi KAWAI ${ }^{1}$ and Hiroshi KONO ${ }^{4}$ \\ ${ }^{1}$ Department of Dental Materials Science, School of Dentistry, Aichi Gakuin University, Nagoya, Japan \\ ${ }^{2}$ Center for Advanced Oral Science, School of Dentistry, Aichi Gakuin University, Nagoya, Japan \\ ${ }^{3}$ Universal Implant Research Institute, Tokyo, Japan \\ ${ }^{4}$ Graduate School of Medical and Dental Sciences, Kagoshima University, Kagoshima, Japan \\ Corresponding author, Seiji BAN; E-mail: sban@g.agu.ac.jp
}

\begin{abstract}
Plate-like specimens were prepared, using a diamond saw, from Cercon - a pre-sintered yttria-stabilized tetragonal zirconia polycrystal (Y-TZP) block. These specimens were treated with 10 kinds of dental materials which acted as contaminants, and then sintered at $1,350^{\circ} \mathrm{C}$ or $1,450^{\circ} \mathrm{C}$. After the final firing, specimens were subjected to a three-point flexural test and Vickers hardness test. Their surfaces were also characterized by scanning electron microscopy and X-ray diffractometry. Phosphoruscontaining contaminants reduced the three-point flexural strength and hardness of final sintered zirconia due to the formation of $\mathrm{YPO}_{4}$ and phase transformation from tetragonal to monoclinic zirconia. Gypsum also reduced both mechanical properties due to the formation of $\mathrm{CaZrO}_{3}$ and phase transformation from tetragonal to cubic zirconia. Other contaminants showed no adverse effects on the mechanical properties of final sintered zirconia.
\end{abstract}

Keywords: Zirconia, Contamination, Sintering, Pre-sintered block, Mechanical property

\section{INTRODUCTION}

With the advent of CAD/CAM technology, yttriastabilized tetragonal zirconia polycrystals (Y-TZP) have become the material of choice for the fabrication of high-quality, all-ceramic dental restorations ${ }^{1,2)}$. To save machining time and produce the least amount of wear and tear on machining tools, many dental CAD/CAM systems use Y-TZP blocks in the pre-sintered state. After machining, pre-sintered zirconia frameworks must be fired according to firing temperatures instructed by the manufacturers. After the final firing, the surfaces of zirconia frameworks are sandblasted (sometimes) and veneered with feldspathic porcelain.

In the oral cavity, dental restorations are subjected to occlusal forces stemming from normal mastication and paranormal bruxing and clenching. They are also exposed to temperature and $\mathrm{pH}$ level fluctuations stemming from the foods and drinks consumed, such as hot versus cold and acidic versus alkaline. Therefore, dental restorations must have sufficiently high mechanical properties to withstand the hostile environment of the oral cavity.

Myriad factors affect the mechanical properties of the final sintered zirconia restorations, running the gamut from chemical composition of zirconia material, restoration design, manufacturing process (hard or soft milling), and firing regime to surface treatment, heat treatment, and bonding to veneering porcelain. We have reported that sandblasting and heat treatment influenced the flexural strength of dental zirconia ${ }^{3,4}$.

Color figures can be viewed in the online issue, which is available at J-STAGE.

Received Aug 11, 2013: Accepted Sep 27, 2013

doi:10.4012/dmj.2013-222 JOI JST.JSTAGE/dmj/2013-222
We also reported that sterilization by autoclaving reduced the flexural strength of Y-TZP due to lowtemperature degradation after long-term storage ${ }^{5,6)}$.

During the machining and firing processes, the surfaces of pre-sintered zirconia are susceptible to contamination because of proximity to other dental materials. We have reported that some contaminants reduced the three-point flexural strengths and hardness of two commercial Y-TZP ceramics ${ }^{7)}$. After firing, both commercial Y-TZP ceramics exhibited crystal phases slightly different from each other, and the mechanical properties of the one fired at higher temperature were more adversely affected. However, it remained to be clarified if these changes were induced by the firing temperature and/or caused by the type of commercial Y-TZP ceramic.

The aim of the present study was to investigate the effects of some dental materials - which acted as contaminants- on the mechanical properties of one commercial Y-TZP ceramic fired at a higher temperature.

\section{MATERIALS AND METHODS}

\section{$Y$-TZP ceramic and contaminants}

Cercon (DeguDent, Hanau, Germany), a pre-sintered Y-TZP ceramic, was selected for this study. Cercon was selected because it was the earliest commercially available Y-TZP ceramic, yet it remains to be one of the most popular zirconia materials frequently employed as a representative Y-TZP material. Slices of platelike specimens $(20 \times 5 \times 1 \mathrm{~mm})$ were sectioned from the zirconia block using a low-speed diamond saw (Isomet, 
Buehler, IL, USA).

Specimens were treated with 10 types of dental materials used as contaminants in this study (Table 1). Given treatment times in Table 1 were thus employed to ensure homogeneous reactions for all dental materials with the zirconia surface.

\section{Flexural strength and Vickers hardness tests}

Contaminated specimens were fired at $1,350^{\circ} \mathrm{C}$ or $1,450^{\circ} \mathrm{C}$ for $2 \mathrm{~h}$. After the final firing, specimens were subjected to a three-point f1exural test and Vickers hardness test. Five specimens were measured for each condition, and their mean and standard deviation values were derived. Data were analyzed with two-way analysis of variance (ANOVA) followed by Dunnett's multiple comparison test, using the specimen group without any contaminants as a control group. All statistical analyses were performed using InStat for Macintosh, Version 3.0 (GraphPad Software Inc., La Jolla, CA, USA).

\section{Surface characterization by SEM and XRD}

Surfaces of the specimens were analyzed by scanning electron microscopy (SEM; JXA-8530FA, JEOL, Tokyo, Japan) and X-ray diffractometry (XRD; Ultima IV, Rigaku, Tokyo, Japan). XRD was performed at $40 \mathrm{kV}$ and $40 \mathrm{~mA}$ over $2 \theta$ angle between 20 and $60^{\circ}$ at $2^{\circ}$ min. XRD patterns were qualitatively analyzed using a computer software, PDXL2 (Rigaku), which used the ICDD (International Center for Diffraction Data) database for phase identification and quantification. Volume fraction of the monoclinic phase was calculated from the relative intensities of the monoclinic peaks at $2 \theta=28.2$ and $31.4^{\circ}$, and that of tetragonal peak at $29.8^{\circ}$ using the equation of Toraya et al. ${ }^{8}$.

\section{Elemental analysis}

Elemental distribution maps of sintered zirconia specimens were acquired using wavelength-dispersive X-ray spectroscopy (WDS; JXA-8530FA, JEOL, Tokyo, Japan) under these operating conditions: applied voltage of $20 \mathrm{kV}$, filament current of $5.0 \times 10^{-8} \mathrm{~A}$, counting time of $20 \mathrm{~ms}$, mapping resolution of $256 \times 192$ pixels, and pixel size of $0.1 \times 0.1 \mu \mathrm{m}$.

\section{RESULTS}

Figure 1 shows the XRD patterns of Y-TZP contaminated with 10 kinds of dental materials after the final firing at $1,450^{\circ} \mathrm{C}$. Diffraction peaks due to formation of new compounds were observed in the patterns of Y-TZP fired with orthophosphoric acid, phosphate-bonded investment powder, phosphate etching gel, and gypsum powder. In the absence of new compounds, diffraction patterns showed only tetragonal zirconia $\left(\mathrm{Y}_{0.037} \mathrm{Zr}_{0.963} \mathrm{O}_{1.982}\right.$, ICDD No.01-083-0113). The XRD

Table 1 Contaminants used in this study

\begin{tabular}{|c|c|c|c|}
\hline No. & Code & Material & Procedure \\
\hline 1 & Orthophos. & $\begin{array}{c}\text { 42.5\% } \mathrm{H}_{3} \mathrm{PO}_{4} \text { acid (Reagent grade, } \\
\text { Wako Pure Chemical, Osaka, Japan) }\end{array}$ & $\begin{array}{l}\text { Specimens were soaked in the solution } \\
\text { for } 10 \mathrm{~s} \text { and washed in distilled water. }\end{array}$ \\
\hline 2 & Phos. Invest. & $\begin{array}{l}\text { Phosphate-bonded investment } \\
\text { (G-Cera Vest, GC, Tokyo, Japan) }\end{array}$ & $\begin{array}{l}\text { Powder was spread on specimen surface } \\
\text { after wetting. }\end{array}$ \\
\hline 3 & Phos. Gel & $\begin{array}{l}\text { Phosphate etching gel (K-Etchant Gel, } \\
\text { Kuraray Dental, Tokyo, Japan) }\end{array}$ & $\begin{array}{l}\text { After gel was swabbed for } 30 \mathrm{~s} \text {, specimens } \\
\text { were washed in distilled water. }\end{array}$ \\
\hline 4 & $\mathrm{HF}$ & $\begin{array}{l}5 \% \text { Hydrofluoric acid (Reagent grade, } \\
\text { Wako Pure Chemical, Osaka, Japan) }\end{array}$ & $\begin{array}{l}\text { Specimens were soaked in the solution } \\
\text { for } 10 \mathrm{~s} \text { and washed in distilled water. }\end{array}$ \\
\hline 5 & Gypsum & $\begin{array}{c}\text { Dental stone } \\
\text { (New Plastone II, GC, Tokyo, Japan) }\end{array}$ & $\begin{array}{c}\text { Powder was spread on specimen surface } \\
\text { after wetting. }\end{array}$ \\
\hline 6 & Wax & $\begin{array}{c}\text { Base plate wax } \\
\text { (Paraffin Wax, GC, Tokyo, Japan) }\end{array}$ & Wax was smeared on specimen surface. \\
\hline 7 & Oil & $\begin{array}{l}\text { Lubricant oil } \\
\text { (Isocut Fluid, Buehler, IL, USA) }\end{array}$ & $\begin{array}{l}\text { Specimens were soaked in the oil for } 10 \mathrm{~min} \\
\text { and wiped with soft paper. }\end{array}$ \\
\hline 8 & Water & Distilled water & $\begin{array}{l}\text { Specimens were soaked in distilled water } \\
\text { for } 10 \mathrm{~min} .\end{array}$ \\
\hline 9 & Sodium Alg. & $\begin{array}{c}\text { Sodium alginate solution } \\
\text { (Acro Sep, GC, Tokyo, Japan) }\end{array}$ & Solution was swabbed on specimen surface. \\
\hline 10 & $\mathrm{NaCl}$ & $\begin{array}{c}\mathrm{NaCl} \text { (Reagent grade, Wako Pure Chemical, } \\
\text { Osaka, Japan) }\end{array}$ & $\begin{array}{c}\text { Powder was spread on specimen surface } \\
\text { after wetting. }\end{array}$ \\
\hline
\end{tabular}




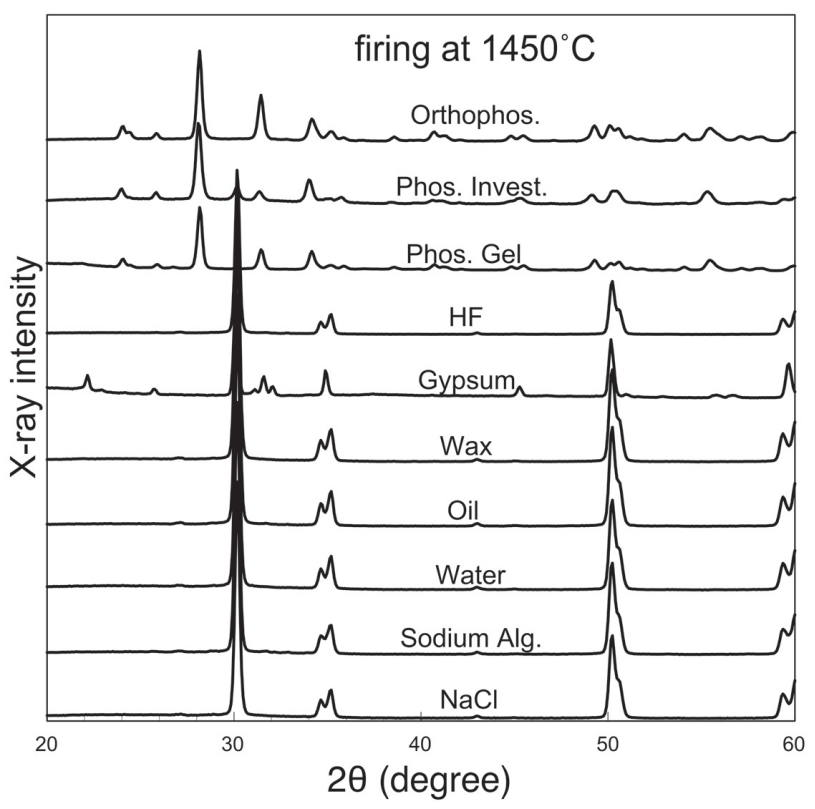

Fig. 1 XRD patterns of Y-TZP fired with 10 kinds of contaminants at $1,450^{\circ} \mathrm{C}$ for $2 \mathrm{~h}$.

patterns of contaminated Y-TZP fired at $1,350^{\circ} \mathrm{C}$ showed similar results (not shown here). Figures 2-5 show the XRD patterns of Y-TZP fired with orthophosphoric acid, phosphate-bonded investment powder, phosphate etching gel, and gypsum powder at 1,350 and $1,450^{\circ} \mathrm{C}$.

After firing with orthophosphoric acid (Fig. 2), phase transformation from tetragonal to monoclinic zirconia (Baddeleyite $\mathrm{ZrO}_{2}$, ICDD No.01-070-2491) occurred, such that no tetragonal phase was detected in final sintered zirconia at both temperatures. A small amount of yttrium phosphate (Xenotime $\mathrm{YPO}_{4}, \mathrm{ICDD}$ No.01-073-1980) was detected. Diffraction peaks due to these new compounds showed higher intensities at higher firing temperature.

After firing with phosphate-bonded investment powder (Fig. 3), phase transformation from tetragonal to monoclinic zirconia occurred and increased with the firing temperature. Monoclinic zirconia content was $45.6 \%$ at $1,350^{\circ} \mathrm{C}$ and $88.8 \%$ at $1,450^{\circ} \mathrm{C}$, whereas tetragonal zirconia content was $54.4 \%$ at $1,350^{\circ} \mathrm{C}$ and $11.2 \%$ at $1,450^{\circ} \mathrm{C}$. A small amount of $\mathrm{YPO}_{4}$ was also detected. Diffraction peaks due to these new compounds showed higher intensities at higher firing temperature.

After firing with phosphate etching gel (Fig. 4), phase transformation from tetragonal to monoclinic zirconia occurred and increased with the firing temperature. A small amount of $\mathrm{YPO}_{4}$ was also detected. Results obtained were similar to those of phosphate-bonded investment powder (Fig. 3), but with lower tetragonal zirconia contents.

After firing with gypsum powder (Fig. 5), phase

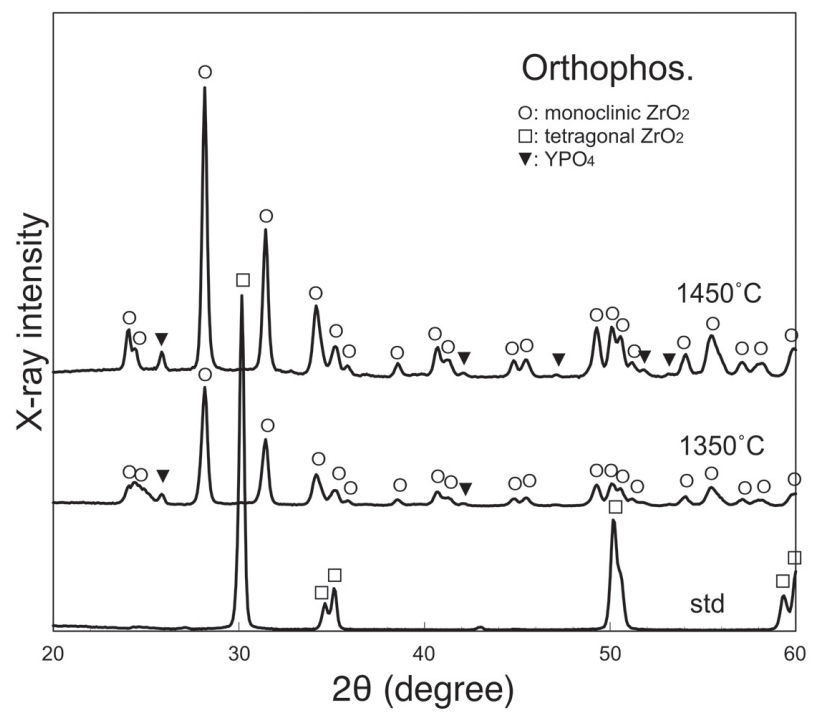

Fig. 2 XRD patterns of Y-TZP fired with orthophosphoric acid at $1,350^{\circ} \mathrm{C}$ and $1,450^{\circ} \mathrm{C}$ for $2 \mathrm{~h}$, and without any contaminants at $1,350^{\circ} \mathrm{C}$ for $2 \mathrm{~h}$ (std).

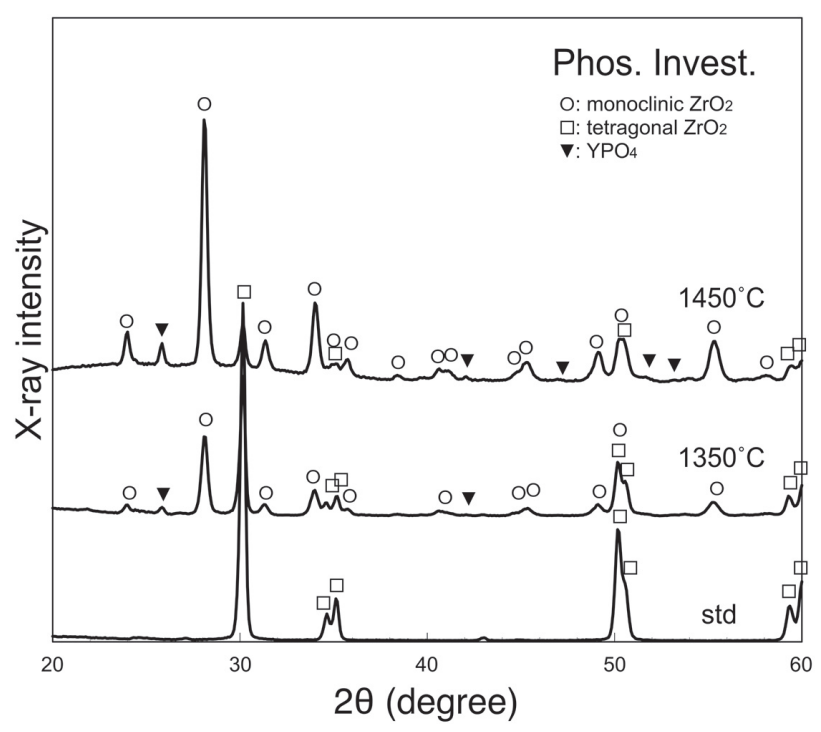

Fig. 3 XRD patterns of Y-TZP fired with phosphatebonded investment powder at $1,350^{\circ} \mathrm{C}$ and $1,450^{\circ} \mathrm{C}$ for $2 \mathrm{~h}$, and without any contaminants at $1,350^{\circ} \mathrm{C}$ for $2 \mathrm{~h}$ (std).

transformation from tetragonal to cubic zirconia $\left(\mathrm{Y}_{0.15} \mathrm{Zr}_{0.85} \mathrm{O}_{1.93}\right.$, ICDD No.00-030-1468) occurred. The formation of calcium zirconate $\left(\mathrm{CaZrO}_{3}\right.$, ICDD No.01076-2401) was detected and increased with the firing temperature. Small amounts of calcium oxide $(\mathrm{CaO}$, ICDD No.01-070-5490) and anhydrite calcium sulfate $\left(\mathrm{CaSO}_{4}, \mathrm{ICDD}\right.$ No.01-075-5972) were also detected.

Figure 6 shows the three-point flexural strengths 


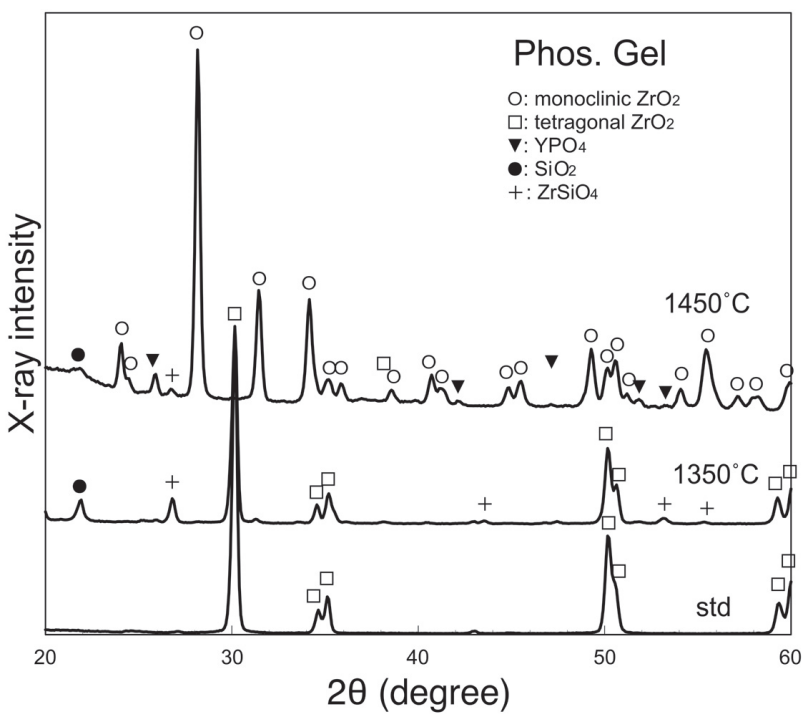

Fig. 4 XRD patterns of Y-TZP fired with phosphate etching gel at $1,350^{\circ} \mathrm{C}$ and $1,450^{\circ} \mathrm{C}$ for $2 \mathrm{~h}$, and without any contaminants at $1,350^{\circ} \mathrm{C}$ for $2 \mathrm{~h}$ (std).

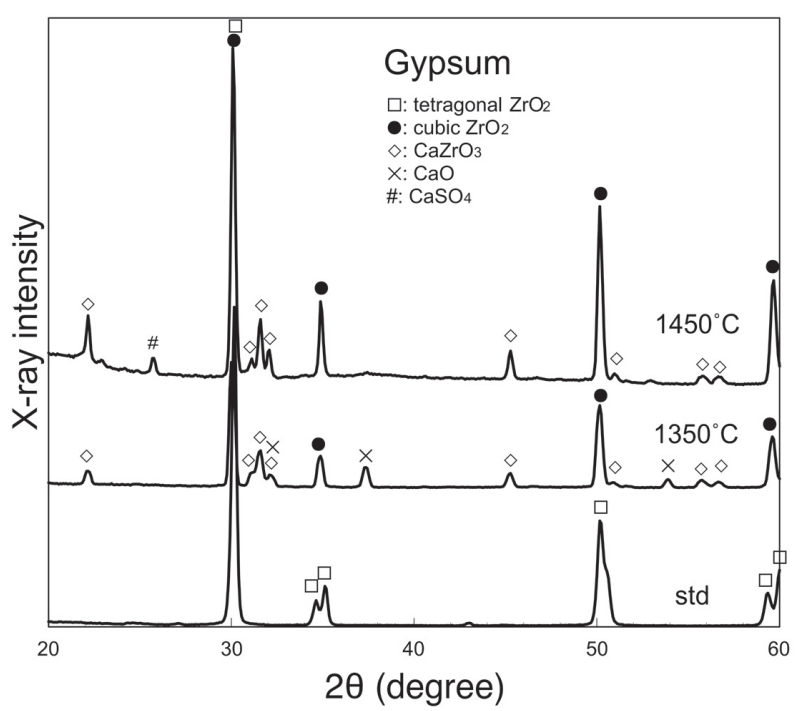

Fig. 5 XRD patterns of Y-TZP fired with gypsum powder at $1,350^{\circ} \mathrm{C}$ and $1,450^{\circ} \mathrm{C}$ for $2 \mathrm{~h}$, and without any contaminants at $1,350^{\circ} \mathrm{C}$ for $2 \mathrm{~h}$ (std).

of Y-TZP with and without 10 kinds of contaminants fired at 1,350 and $1,450^{\circ} \mathrm{C}$ for $2 \mathrm{~h}$. Firing with orthophosphoric acid, phosphate-bonded investment powder, phosphate etching gel, and gypsum powder at both temperatures significantly reduced the three-point flexural strength of Y-TZP, when compared to final sintered zirconia without any contaminants $(p<0.01)$. On the other hand, the flexural strength of Y-TZP without any contaminants slightly increased with the

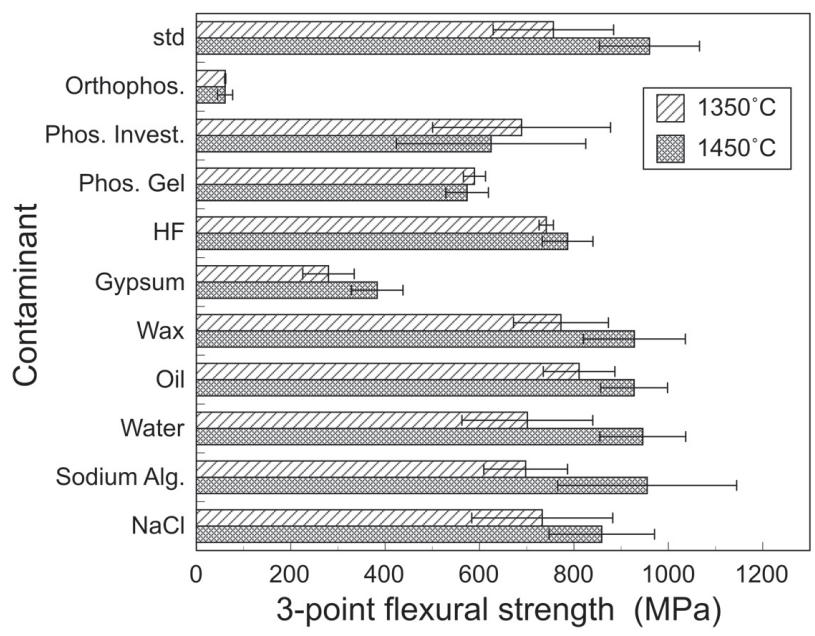

Fig. 6 Three-point flexural strengths of Y-TZP fired with and without 10 kinds of contaminants at $1,350^{\circ} \mathrm{C}$ and $1,450^{\circ} \mathrm{C}$ for $2 \mathrm{~h}$.

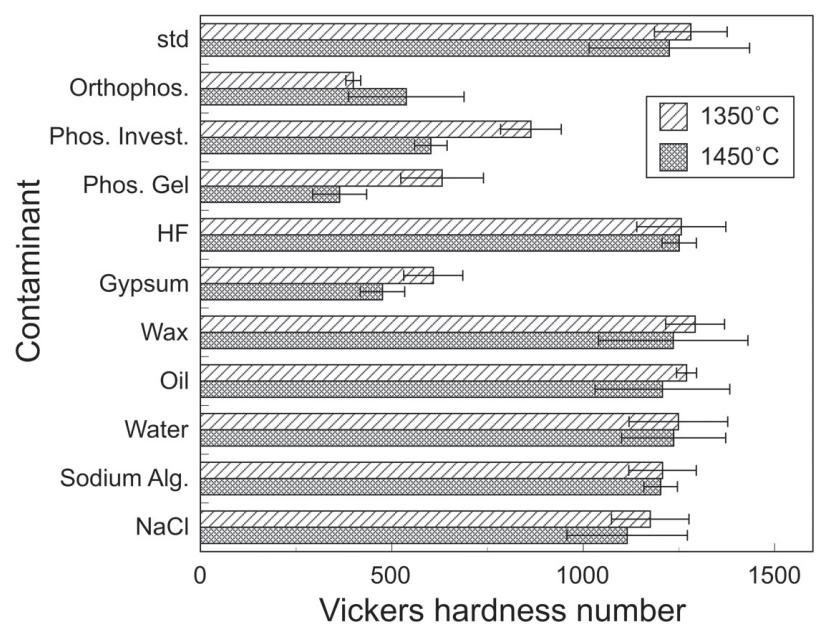

Fig. 7 Vickers hardness values of Y-TZP fired with and without 10 kinds of contaminants at $1,350^{\circ} \mathrm{C}$ and $1,450^{\circ} \mathrm{C}$ for $2 \mathrm{~h}$.

firing temperature $(p<0.05)$.

Figure 7 shows the Vickers hardness values of Y-TZP with and without 10 kinds of contaminants fired at 1,350 and $1,450^{\circ} \mathrm{C}$ for $2 \mathrm{~h}$. Firing with orthophosphoric acid, phosphate-bonded investment powder, phosphate etching gel, and gypsum powder at both temperatures significantly reduced the Vickers hardness of Y-TZP, when compared to final sintered zirconia without any contaminants $(p<0.01)$. Changes in Vickers hardness were similar to those of flexural strength (Fig. 6), except that the hardness of Y-TZP fired with phosphate-bonded investment powder and 
phosphate etching gel at $1,450^{\circ} \mathrm{C}$ were significantly lower than those at $1,350^{\circ} \mathrm{C}(p<0.01)$.

Figure 8 shows the secondary electron images (SEI) of the surfaces of Y-TZP with and without the abovementioned property-altering contaminants fired at $1,450^{\circ} \mathrm{C}$. The surface of pre-sintered Y-TZP block (Fig. 8(a)) showed a porous structure consisting of small grains of $100-200 \mathrm{~nm}$ in size. Judging from the XRD analyses (Fig. 1), these small grains seemed to be tetragonal zirconia. The surface of Y-TZP fired without any contaminants (Fig. 8(b)) showed the normally sintered and dense structure with fine grains of 300$400 \mathrm{~nm}$. The surfaces of Y-TZP contaminated with orthophosphoric acid (Fig. 8(c)), phosphate-bonded investment powder (Fig. 8(d)), and phosphate etching gel (Fig. 8(e)) showed larger grains of 1-2 $\mu \mathrm{m}$. Besides, the surfaces contaminated with orthophosphoric acid (Fig. 8(c)) and phosphate etching gel (Fig. 8(e)) revealed the presence of cracks - especially a conspicuous wide crack with orthophosphoric acid. Judging from the XRD analyses (Figs. 2-4), these large grains seemed to be monoclinic zirconia. The surface contaminated with gypsum powder (Fig. 8(f)) showed markedly larger grains which were bigger than $10 \mu \mathrm{m}$.

Figure 9 shows the elemental distribution maps of zirconium ( $\mathrm{Zr})$, yttrium $(\mathrm{Y})$, and phosphorus $(\mathrm{P})$ together with the SEI of the section of Y-TZP fired with phosphate-bonded investment powder at $1,450^{\circ} \mathrm{C}$. Dark particles dispersed in the near-surface area were rich in $\mathrm{Y}$ and $\mathrm{P}$ but poor in $\mathrm{Zr}$. From the XRD analyses (Fig. 3), these particles might be $\mathrm{YPO}_{4}$.

Figure 10 shows the elemental distribution maps of zirconium (Zr), yttrium (Y), and calcium (Ca) together with the SEI of the section of Y-TZP fired with gypsum powder at $1,450^{\circ} \mathrm{C}$. The surface layer, about $10 \mu \mathrm{m}$ thick, was rich in $\mathrm{Ca}$ but poor in $\mathrm{Zr}$ and Y. From the XRD analyses (Fig. 5), this layer might consist of $\mathrm{CaZrO}_{3}$.
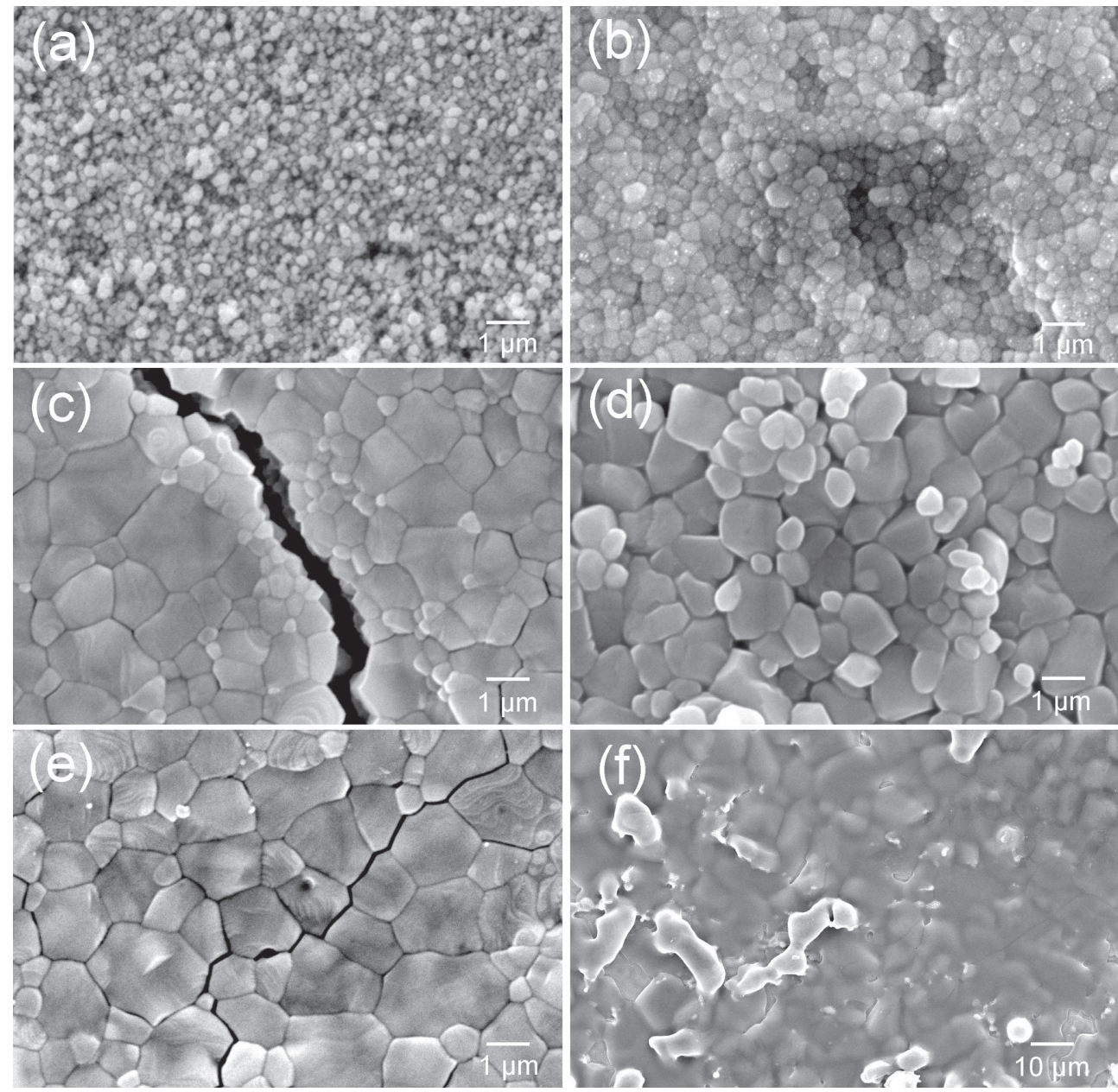

Fig. 8 SEI of the surfaces of Y-TZP fired with and without contaminants at $1,450^{\circ} \mathrm{C}$.

(a) pre-sintered block; (b) without any contaminants; (c) contaminated with orthophosphoric acid; (d) contaminated with phosphate-bonded investment powder; (e) contaminated with phosphate etching gel; and (f) contaminated with gypsum powder. 

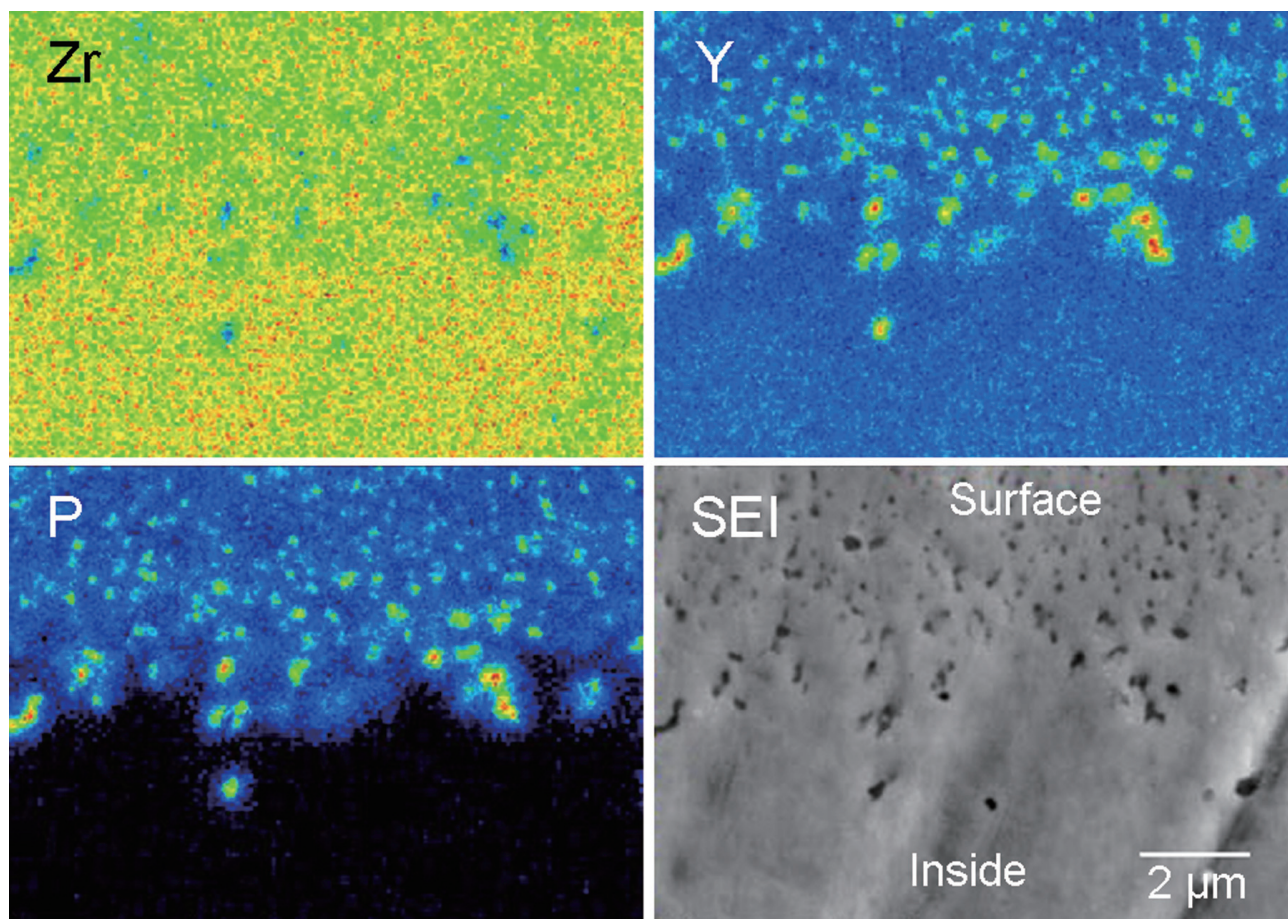

Fig. 9 Elemental distribution maps of zirconium (Zr), yttrium (Y), and phosphorus (P) together with SEI of the section of Y-TZP fired with phosphate-bonded investment powder at $1,450^{\circ} \mathrm{C}$.
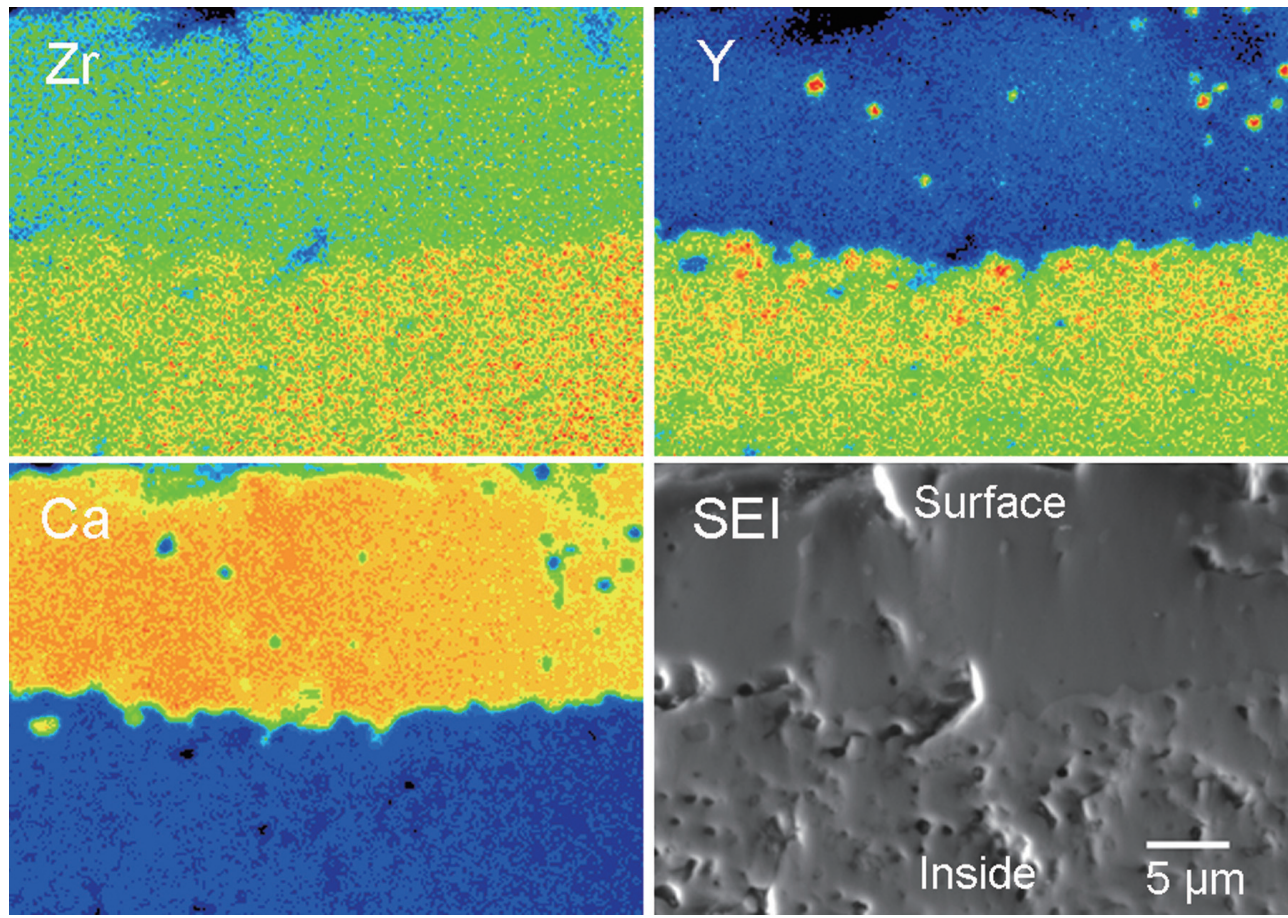

Fig. 10 Elemental distribution maps of zirconium (Zr), yttrium (Y), and calcium (Ca) together with SEI of the section of Y-TZP fired with gypsum powder at $1,450^{\circ} \mathrm{C}$. 


\section{DISCUSSION}

\section{Choice of contaminants}

The contaminants selected for this study were chemical compounds generally used in dental clinics and laboratories ${ }^{9}$. Contaminants associated with casting were namely phosphate-bonded investment powder (No. 2), water (No. 8), gypsum (No. 5), sodium alginate (No. 9), and sodium chloride (No. 10). Phosphate-bonded investment powder (No. 2), which mainly consisted of $\mathrm{SiO}_{2}, \mathrm{MgO}$, and $\mathrm{NH}_{4} \mathrm{H}_{2} \mathrm{PO}_{4}$, is used for casting highmelting alloys ${ }^{10)}$. Water (No. 8) is a good solvent for many materials, such as being mixed with investment powder to prepare investment casting slurry. Gypsum or dental stone powder (No. 5), which mainly consisted of calcium phosphate hemihydrate $\left(\mathrm{CaSO}_{4} \cdot 1 / 2 \mathrm{H}_{2} \mathrm{O}\right)$, is typically used for making casts for diagnostic purposes and for complete and partial denture construction. Sodium alginate solution (No. 9), which mainly consisted of water, sodium alginate, and food dye ${ }^{11)}$, is used as a mold separator for heat-polymerized acrylic resins. Sodium chloride (No. 10) is added in small quantities to accelerate the setting reaction of gypsum products such as models and molds ${ }^{9}$.

Contaminants associated with surface pretreatment and luting of zirconia ceramics were namely phosphate etching gel (No. 3), hydrofluoric acid (No. 4), and orthophosphoric acid (No. 1). Phosphate etching gel (No. 3), which mainly consisted of distilled water, $35-45 \%$ orthophosphoric acid, and a viscosity agent such as colloidal silica ${ }^{12)}$, is an etching agent used to etch tooth enamel for resin composite fillings. It is also used as a cleaning agent in the pretreatment of ceramic restorations such as porcelain jacket crowns and porcelain veneers. Similarly, 5\% hydrofluoric acid (No. 4) is used for pretreatment of porcelain restorations for bonding to teeth ${ }^{13,14)}$. Zinc phosphate cement is commonly used as a luting agent for zirconia cores, and $42.5 \%$ orthophosphoric acid (No. 1) is similar to the mixing liquid used to prepare zinc phosphate cement. Orthophosphoric acid is also used as an electrolyte for electrolytic/electrochemical etching of metal-based dentures.

Organic materials needed for routine dental laboratory procedures were namely base plate wax (No. 6) and lubricant oil (No. 7). Wax (No. 6), which consisted of paraffin, beeswax, carnauba, and dammar resin ${ }^{15)}$, is mainly used to make base plates and wax rims for complete and partial denture construction. Lubricant oil (No. 7) is produced by distilling petroleum under vacuum and mainly consisted of volatile organic compounds ${ }^{16}$. It is commonly used as a lubricant for diamond saws.

Powder-like materials (Nos. 2, 5, and 10) contaminate by floating and dispersing in the air of dental laboratories, before eventually settling on the surfaces of zirconia blocks. Liquids (Nos. 1, 4, 7, 8, and 9), gel (No. 3), and flexible materials (No. 6) may cause the inadvertent or accidental contamination of zirconia blocks through operators' hands and tools.

\section{Reaction with phosphorus-containing contaminants}

Final firing of Y-TZP contaminated with phosphoruscontaining dental materials such as orthophosphoric acid (No. 1), phosphate-bonded investment powder (No. 2), and phosphate etching gel (No. 3) showed the formation of new products such as $\mathrm{YPO}_{4}$ and monoclinic $\mathrm{ZrO}_{2}$. Amounts of both products formed increased with the firing temperature.

$\mathrm{YPO}_{4}$ was formed as granules on Y-TZP surface in contact with the contaminants (Fig. 9). It seemed that some $\mathrm{Y}$ content in the surface tetragonal $\mathrm{ZrO}_{2}$ grains was consumed to produce $\mathrm{YPO}_{4}$. Further depletion of $\mathrm{Y}$ content from the tetragonal $\mathrm{ZrO}_{2}$ grains inside the specimen caused the tetragonal grains to transform into the monoclinic phase. A decrease in $\mathrm{Y}$ content compromised the stability of the tetragonal phase and resulted in the phase transformation from tetragonal to monoclinic zirconia. Relatedly, flexural strength decreased with an increase in monoclinic phase (Fig. 6), yielding alarmingly and significantly low flexural strengths after firing with orthophosphoric acid at both temperatures. SEI revealed the presence of large microcracks (Fig. 8) caused by large volume expansion, which occurred with the transformation from tetragonal to monoclinic phase.

Interestingly, Vickers hardness after firing with orthophosphoric acid seemed comparable to contamination with other phosphorus-containing materials (Fig. 7). It was probably because being a liquid, orthophosphoric acid seeped into and penetrated beneath the surface into the porous network of Y-TZP specimens upon contact. It then deeply and widely propagated the damage by causing tetragonal-tomonoclinic phase transformation inside the entire specimen body, but causing less damage on the surface. On the other hand, contamination with solid and gel materials caused substantial damage to the surfaces in contact because of their adherence to the surface.

Across the three phosphorus-containing contaminants used in this study, they had one common ingredient -orthophosphoric acid. In the case of phosphate etching gel, it also contained colloidal silica as a viscosity agent. However, up to the firing temperature of $1,450^{\circ} \mathrm{C}$, reaction between silica and Y-TZP remained negligible. Instead, phosphatebonded investment powder reacted with water on the pre-sintered Y-TZP surface during the contamination treatment procedure and set with the formation of magnesium ammonium phosphate as follows ${ }^{17)}$ :

$$
\mathrm{MgO}+\mathrm{NH}_{4} \mathrm{H}_{2} \mathrm{PO}_{4}+5 \mathrm{H}_{2} \mathrm{O} \rightarrow \mathrm{NH}_{4} \mathrm{MgPO}_{4} \cdot 6 \mathrm{H}_{2} \mathrm{O}
$$

With heating, it decomposed as follows:

$$
\begin{aligned}
& 2 \mathrm{NH}_{4} \mathrm{MgPO}_{4} \cdot 6 \mathrm{H}_{2} \mathrm{O} \rightarrow \mathrm{Mg}_{2} \mathrm{P}_{2} \mathrm{O}_{7}+2 \mathrm{NH}_{3}+13 \mathrm{H}_{2} \mathrm{O}, \\
& 2 \mathrm{NH}_{4} \mathrm{H}_{2} \mathrm{PO}_{4} \rightarrow \mathrm{P}_{2} \mathrm{O}_{5}+2 \mathrm{NH}_{3}+3 \mathrm{H}_{2} \mathrm{O}
\end{aligned}
$$

For the zirconia surface in contact with the investment, zirconia probably reacted with $\mathrm{P}_{2} \mathrm{O}_{5}$ as follows: 


$$
\mathrm{ZrO}_{2}+\mathrm{P}_{2} \mathrm{O}_{5} \rightarrow \mathrm{ZrP}_{2} \mathrm{O}_{7}
$$

In our previous study ${ }^{18)}$, we investigated the reaction between zirconia and phosphate-bonded investment at the temperature range of $850-1,100^{\circ} \mathrm{C}$. When fired at 850 and $950^{\circ} \mathrm{C}, \mathrm{ZrP}_{2} \mathrm{O}_{7}$ was detected. When fired at 1,080 and $1,100^{\circ} \mathrm{C}$, only $\mathrm{YPO}_{4}$ and monoclinic zirconia were detected, but no $\mathrm{ZrP}_{2} \mathrm{O}_{7}$. When firing temperature was above $1,080^{\circ} \mathrm{C}$, it could be assumed that $\mathrm{ZrP}_{2} \mathrm{O}_{7}$ reacted with Y-TZP as follows:

\section{$\mathrm{ZrP}_{2} \mathrm{O}_{7}+100$ tetragonal $\left(\mathrm{Y}_{2} \mathrm{O}_{3}\right)_{0.03}\left(\mathrm{ZrO}_{2}\right)_{0.97}$}

$\rightarrow 6 \mathrm{YPO}_{4}+98$ monoclinic $\mathrm{ZrO}_{2}$

The formation of $\mathrm{YPO}_{4}$ required only a small amount of phosphate ions to react with a fairly large amount of Y-TZP. The depletion of Y content then resulted in the formation of a large amount of monoclinic zirconia. In the present study, the firing temperatures of 1,350 and $1,450{ }^{\circ} \mathrm{C}$ were higher than the previous firing temperature range of $850-1100^{\circ} \mathrm{C}^{18)}$, thus heightening the formation of both $\mathrm{YPO}_{4}$ and monoclinic zirconia.

This was the reason why the final sintered zirconia contaminated with orthophosphoric acid (No. 1) showed only the formation of $\mathrm{YPO}_{4}$ and monoclinic zirconia, but no tetragonal zirconia. In the case of phosphate-bonded investment powder (No. 2) and phosphate etching gel (No. 3), the intrinsic amount of orthophosphoric acid in them was smaller than that in orthophosphoric acid solution (No. 1). Therefore, a small amount of tetragonal zirconia was detected in their XRD patterns (Figs. 3 and 4).

The spontaneous surface reactions between zirconia and phosphorus-containing compounds could be attributed to the quick adsorption of phosphate ions on the surface of pre-sintered zirconia. This explained why phosphate monomer-containing primers showed good bonding strength to zirconia ${ }^{19)}$. Watari et al. also reported that reaction between zirconia powder and phosphate initiated a setting reaction ${ }^{20}$. These results indicated that phosphates could react well with zirconia at a wide range of temperatures.

\section{Reaction with calcium-containing contaminants}

$\mathrm{X}$-ray diffraction analysis revealed that final sintering with gypsum formed new products such as $\mathrm{CaO}, \mathrm{CaZrO}_{3}$, and cubic zirconia (Fig. 5). SEM observation showed that the surface was completely covered with these new products (Fig. 8). Flexural strength and Vickers hardness decreased with an increase in cubic phase (Figs. 6 and 7).

When gypsum was applied on the wetted surface of pre-sintered Y-TZP, calcium sulfate hemihydrate was converted to calcium sulfate dihydrate. When the latter was heated, the following conversions took place:

$$
\begin{aligned}
& \mathrm{CaSO}_{4} \cdot 2 \mathrm{H}_{2} \mathrm{O} \rightarrow \mathrm{CaSO}_{4} \cdot 1 / 2 \mathrm{H}_{2} \mathrm{O}+3 / 2 \mathrm{H}_{2} \mathrm{O} \uparrow \text { (up to } \\
& 130^{\circ} \mathrm{C} \text { ), } \\
& \mathrm{CaSO}_{4} \cdot 1 / 2 \mathrm{H}_{2} \mathrm{O} \rightarrow \mathrm{CaSO}_{4}+1 / 2 \mathrm{H}_{2} \mathrm{O} \uparrow\left(\text { up to } 200^{\circ} \mathrm{C}\right. \text { ), } \\
& \mathrm{CaSO}_{4} \rightarrow \mathrm{CaO}+\mathrm{SO}_{2} \uparrow+1 / 2 \mathrm{O}_{2} \uparrow\left(960^{\circ} \mathrm{C}\right)
\end{aligned}
$$

At higher temperature, $\mathrm{CaO}$ reacted with $\mathrm{ZrO}_{2}$ as follows:

$$
\mathrm{CaO}+\mathrm{ZrO}_{2} \rightarrow \mathrm{CaZrO}_{3}
$$

$\mathrm{CaZrO}_{3}$ was formed on the surface of final sintered zirconia, and its amount increased with the firing temperature. This meant that a higher temperature, formation of cubic zirconia also increased as follows:

$$
\begin{aligned}
& \mathrm{xCaO}+\text { tetragonal }\left(\mathrm{Y}_{2} \mathrm{O}_{3}\right)_{0.03}\left(\mathrm{ZrO}_{2}\right)_{0.97} \\
& \rightarrow \text { cubic }(\mathrm{CaO})_{\mathrm{x}}\left(\mathrm{Y}_{2} \mathrm{O}_{3}\right)_{0.03}\left(\mathrm{ZrO}_{2}\right)_{0.97}
\end{aligned}
$$

For this reason, $\mathrm{CaO}$ can act as a stabilizer for cubic zirconia $^{21)}$.

\section{Reaction with other contaminants}

There were no significant changes in the microstructure and mechanical properties of final sintered zirconia contaminated with organic materials such as wax (No. 6) and oil (No. 7), volatile compounds such as hydrofluoric acid (No. 4) and water (No. 8), and sodium compounds such as sodium alginate (No. 9) and sodium chloride (No. 10).

The organic compounds were already burned out at $400-500^{\circ} \mathrm{C}$, and small amounts of impurities remaining in them did not affect the surface of zirconia. Hydrofluoric acid solution most probably decomposed before any reaction with zirconia could take place. Water vaporized and disappeared from the zirconia surface at $100^{\circ} \mathrm{C}$. Sodium ions hardly substituted zirconium ions because of differences in valence number and hardly inserted into the lattice because of ion size.

\section{CONCLUSIONS}

Within the limitations of the present study, the following conclusions were drawn:

1. When Y-TZP was fired with phosphoruscontaining compounds such as orthophosphoric acid, phosphate-bonded investment powder, and phosphate etching gel, $\mathrm{YPO}_{4}$ was formed and concomitantly the transformation from tetragonal to monoclinic zirconia occurred. Mechanical properties decreased with an increase in monoclinic phase.

2. When Y-TZP was fired with gypsum powder, $\mathrm{CaZrO}_{3}$ and cubic zirconia were formed, causing a decrease in mechanical properties.

3. Decreases in mechanical properties due to the presence of and reaction with contaminants became more severe with increase in the firing temperature. In the absence of contaminants, the flexural strength of Y-TZP increased with the firing temperature.

4. The contaminant compounds used in this study are generally used in dental clinics and laboratories, which may cause inadvertent or accidental contamination to pre-sintered zirconia blocks before the final firing. Therefore, zirconia 
blocks should be isolated and stored in a clean state before machining. Sintering is preferably performed immediately after machining to reduce the exposure to contaminants.

\section{ACKNOWLEDGMENTS}

This work was partially supported by a Grant-in-aid for General Scientific Research from the Japan Society for the Promotion of Science (C-24592960).

\section{REFERENCES}

1) Piconi C, Maccauro G. Zirconia as a ceramic biomaterial. Biomaterials 1999; 20: 1-25.

2) Ban S. Reliability and properties of core materials for allceramic dental restorations. J Dent Sci Rev 2008; 44: 3-21.

3) Ban S, Sato H, Nawa M, Suehiro Y, Nakanishi H. Effect of sandblasting and heat treatment on biaxial flexure strength of the zirconia/alumina nanocomposite. Key Eng Mater 2007; 330-332: 353-356.

4) Sato H, Yamada K, Pizzotti G, Nawa M, Ban S. Mechanical properties of dental zirconia ceramics changed with sandblasting and heat treatment. Dent Mater J 2008; 27: 408-414.

5) Ban S, Nawa M, Suehiro Y, Nakanishi H. Mechanical properties of zirconia/alumina nano-composite after soaking in various water-based conditions. Key Eng Mater 2006; 309311: 1219-1222.

6) Ban S, Sato H, Suehiro Y, Nakanishi H, Nawa M. Biaxial flexure strength and low temperature degradation of Ce-TZP/ $\mathrm{Al}_{2} \mathrm{O}_{3}$ nanocomposite and Y-TZP as dental restoratives. $\mathrm{J}$ Biomed Mater Res B Appl Biomater 2008; 87B: 492-498.

7) Okuda Y, Noda M, Tsuruki J, Ban S. Property change of dental zirconia with contamination during final firing. Arch Bioceram Res 2010; 10: 70-73.

8) Toraya H, Yoshimura M, Somiya S. Calibration curve for quantitative analysis of the monoclinic-tetragonal $\mathrm{ZrO}_{2}$ system by X-ray diffraction. J Am Ceram Soc 1984; 67: C119-C121.

9) Gladwin M, Bagby M. Clinical aspects of dental materials: theory, practice, and cases. 3rd ed. Philadelphia: Wolters Kluwer/Lippincott Williams \& Wilikins; 2009. p. 21-32.

10) Asaoka K, Bae JY, Lee HH. Porosity of dental phosphatebonded investments after setting and heating processes. Dent Mater J 2012; 31: 835-842.

11) Material Safety Data Sheet, GC, Acro Sep, ID No.10-2-056, prepare 2010/08/30.

12) Material Safety Data Sheet, Kuraray, K-etchant gel, review 2012/04/01.

13) Chaiyabutr Y, McGowan S, Phillips KM, Kois JC, Giordano RA. The effect of hydrofluoric acid surface treatment and bond strength of a zirconia veneering ceramic. J Prosthet Dent 2008; 100: 194-202.

14) Addison O, Marquis PM, Fleming GJP. The impact of hydrofluoric acid surface treatments on the performance of a porcelain laminate restorative material. Dent Mater 2007; 23: 461-468.

15) Material Safety Data Sheet, GC, Paraffin wax, ID No.03-2053, prepare 2003/04/10.

16) Material Safety Data Sheet, Buehler, Isocut Fluid, ID No.111193-032, prepare 2012/04/03.

17) Neiman R, Sarma AC. Setting and thermal reactions of phosphate investments. J Dent Res 1980; 59: 1478-1485.

18) Yoshihara K, Ban S, Kawai T, Tanaka Y. Reaction of zirconia with phosphate-bonded investment for heat pressing technique. Key Eng Mater 2013; 529-530: 537-542.

19) Kern M, Barloi A, Yang B. Surface conditioning influences zirconia ceramic bonding. J Dent Res 2009; 88: 817-822.

20) Watari F, Nishimura F, Fukumoto R, Nomoto S. Zirconia investment. J J Dent Mater 1987; 6: 212-217.

21) Wang $\mathrm{H}$, Wang $\mathrm{M}$, Zhao N, Wei W, Sun $\mathrm{Y}$. $\mathrm{CaO}-\mathrm{ZrO}_{2}$ solid solution: A highly stable catalyst for the synthesis of dimethyl carbonate from propylene carbonate and methanol. Catalysis Lett 2005; 105: 253-257. 